\title{
From technology speculation to value creation: The changing discourse and actants in the construction of IoT on Twitter by Mathilda Åkerlund and Daniel Nylén
}

\begin{abstract}
The Internet of Things (IoT) is rapidly becoming an important technology, affecting our everyday lives, and is predicted to do so even more extensively in the coming years. Still, the concept remains somewhat fuzzy. As IoT continues to grow in importance and scope, so does the need to understand how the concept is used and what it represents. This study analyzes over nine million tweets over an extended sample period, applying a mixed methods approach to investigate how IoT is understood on Twitter over time, and importantly, the human and non-human actors that were prolific in shaping the discourse. The findings reveal a changing focus within the IoT discourse over time - from a primary technological, engineering perspective to one which highlighted practical implementations and particularly ways of leveraging IoT solutions to cultivate service innovation and generate novel forms of value creation. However, the scholarly community is not keeping up with this change. Furthermore, the analysis shows that over time, bots become increasingly prominent in tweeting IoT-related content, at the expense of individual Twitter users. This finding puts into new light the question of who shapes emerging technological concepts and the accountability and agency of bots.
\end{abstract}

\section{Contents}

1. Introduction

2. The Internet of Thing $\underline{s}$

3. Research design

4. The evolution the IoT discourse on Twitter

$\underline{\text { 5. Concluding discussion }}$

\section{Introduction}

The Internet of Things (IoT) is rapidly becoming an important technology, affecting our everyday lives, and is predicted to do so even more extensively in the coming years. Still, the concept remains somewhat fuzzy. Scholarly conceptualizations and understandings of IoT cultivated thus far vary considerably. Atzori, et al. [1] noted how the interest in IoT within the research community has resulted in numerous definitions of the term and highlight the "difficulty in understanding what IoT really means, which basic ideas stand behind this concept, and which social, economical and technical implications the full deployment of IoT will have". More recent literature similarly note that these definitions remain underdeveloped (Goumagias, et al., 2021). Consequently, insights into the processes and outcomes of IoT's practical enactment, as well as its potential organizational and societal impacts remain imprecise (e.g., Adat and Gupta, 2018; Singh, et al., 2014; Wortmann and Flüchter, 2015). As IoT continues to grow in importance and scope, so does the need to understand how the concept is used and what it represents.

To gain insight into these issues it is necessary to explore the meanings which are, and have been, attached to the IoT concept in various arenas. Social media is one such arena in which represents a valuable entry point into the formation of public opinion and discourse (Chen and Tomblin, 2021; Dong and Lian, 2021; Kane, et al., 2014), specifically emerging concepts such as IoT which might be particularly open to (re)definitions due to their ambiguity and fuzziness. 
While scholars have stressed the importance of theoretical and practical contributions from multiple fields in furthering knowledge of IoT (Atzori, et al., 2010; Lee, et al., 2017), the challenge remains that an engineering perspective dominates extant research (Mishra, et al., 2016; Nicolescu, et al., 2018; Riggins and Wamba, 2015). In seeking to add new knowledge of the IoT concept from a social science perspective (Lee, et al., 2017), we analyze over nine million posts collected from Twitter over an extended period of time, applying an empirically driven, mixed methods approach. In so doing, we ask (RQ1) How is IoT constructed as a concept on Twitter over time? Furthermore, because new technological concepts and digital "fashions" (Wang, 2010) such as IoT are discursively constructed by someone, empirical studies must investigate the human, corporate and technological actors which are important for this discursive construction. Therefore, in paying attention to various both human and non-human actors (Latour, 1996), we also consider (RQ2) What types of actors are important for this discursive construction?

The remainder of this paper is structured as follows. The next section provides insight into previous research on IoT and the theoretical perspective of the study. This is proceeded by a section on research design and the ethical considerations of the study. Subsequently, follows our empirical findings, and then lastly a concluding discussion and limitations and directions for future research.

\section{The Internet of Things}

\subsection{The IoT concept}

The IoT concept was introduced by Ashton (2009) in a 1999 presentation at Procter \& Gamble, as he referred to the linking of radio-frequency identification (RFID) to the internet. Over the years, and in various contexts, the concept has come to mean range of different things. It has been defined simply as "things belonging to the Internet" [2] and as encompassing the overall enhancement of "things" through globally connected digital services (Wortmann and Flüchter, 2015). Other definitions incorporate both the interconnectedness of devices to other entities, as well as to networks (Gubbi, et al., 2013; Maras, 2015).

In their review of scholarly literature covering IoT, Lee, et al. [3] find four reoccurring definitions. First, IoT as "intelligent objects", emphasizing identity, intelligent interface, and inter-connectedness of objects. Second, as "an extension of the Internet" through "things" not traditionally considered computers that are connected to the Internet. Third, as a "global network infrastructure" connecting objects at a large scale through standardized communications protocols. In the last type of definitions identified by Lee, et al. (2017) IoT is seen as the "interaction of information", focusing specifically on the information exchange between "things".

With this range of different understandings, the ambiguity of IoT as a concept is apparent, and scholars are in agreement on this issue (Olson, et al., 2015; Singh, et al., 2014; Wortmann and Flüchter, 2015; Yan, et al., 2015). Atzori, et al. (2010) argue that this ambiguity can be traced back to the two words which constitute it, where "Internet" suggests IoT to be network oriented, while "things" denotes common, household objects. Against this background, there is a need to understand more broadly the meanings which are attached to the IoT concept in order to ascertain the societal implications of the technology (see also Olson, et al.., 2015).

\subsection{Previous research on IoT}

While research efforts to understand IoT have been going on for over two decades, the focus of research has often remained somewhat narrow in scope. More concretely, throughout this extended time period, scholars have studied various aspects of IoT implementation, including the potentials of IoT in the defense industry (Fraga-Lamas, et al., 2016; Payal, et al., 2021), in healthcare (Farahani, et al., 2018; Said, et al., 2021; Yeh, 2016), and in agriculture (Brewster, et al., 2017; Mohanraj, et al., 2016). Although there is a variation in IoT contexts and domains examined, engineering perspectives have often dominated IoT research (Olson, et al., 2015; Riggins and Wamba, 2015). This dominance becomes especially apparent in Lee, et al.'s (2017) research overview: Although the authors deliberately excluded studies applying an engineering perspective, they found that many articles were written by engineering scholars, and focused on industrial issues. Correspondingly, Yan, et al. (2015) found that the most frequently used keywords in academic publishing regarding IoT are technological terms including "Wireless sensor networks", "RFID", and "Cloud computing".

Some recent efforts have begun approaching IoT from a sociotechnical perspective, and a handful of studies have been published in leading outlets thus far. These efforts have explored IoT diffusion and adoption (Dong, et al., 2017; Kadylak and Cotten, 2020; van Deursen, et al., 2021) and value creation (Nicolescu, et al., 2018; Velsberg, et al., 2020). A handful have also begun exploring how IoT is understood online. Broadly, the studies have shown that the most commonly discussed topics are business opportunities, and technological issues and applications (Bian, et al., 2016; Liu and Zhang, 2018; Zubiaga, et al., 2018). A majority of IoT related content is found to be either neutral or positive, with the exception for privacy and security concerns 
(Bian, et al., 2016; Liu and Zhang, 2018; Zubiaga, et al., 2018) - topics which have gained increasing importance over time in social media discussions (Chae, 2019). Two other topics which have increased in prominence are big data analytics and artificial intelligence, which have been identified in previous research as increasingly important topics in relation to IoT on social media (Chae, 2019; Zubiaga, et al., 2018).

As noted by Riggins and Wamba (2015), capturing data from social media feeds holds great promise for those who seek to gain a better understanding of the usage, impact, and adoption of IoT. More than this, it might provide a different perspective on IoT, not the least as previous research indicates discrepancies between understandings of IoT in academia and on social media (Kumar, et al., 2020).

While empirical work carried out by extant literature so far provides important insights into the social media discourse on IoT, previous research efforts also include several limitations. Notably, in regard to understandings changes in the IoT discourse over time, where extant literature has often been hampered by inconsistently sampled datasets covering short time periods (Bian, et al., 2016; Kumar, et al., 2020; Liu and Zhang, 2018). While some scholars have indeed analyzed IoT on social media based on longitudinal datasets, these studies have all relied solely on quantitative text analysis methods such as topic modelling and sentiment analysis (Chae, 2019; Zubiaga, et al., 2018). While providing valuable overviews of IoT, these studies do not cultivate a qualitative understanding of the meaning of overarching patterns.

When it comes to analyses of the important actors who contribute to shaping IoT on Twitter, studies have slowly begun noting the role of the user in the formation of "user-generated content". However, these have previously focused on those actors who are mentioned by others (Kumar, et al., 2020) or focused on those who are expected to be influential (Ustek-Spilda, et al., 2021), rather than focusing on those who are prolific in contributing content that shapes this issue. Furthermore, while Zubiaga, et al. (2018) identified that 38,8 percent of those posting about IoT are human based on their Twitter names, they do not focus on what nonhuman actors are posting. Our analysis responds to these limitations in two principal ways: (1) by quantitatively and qualitatively investigating how IoT is discussed on Twitter; and, (2) by exploring who contributes to shaping this discourse over time.

\subsection{IoT on Twitter: A discursive perspective}

Social media sites constitute important places for the formation and distribution of public opinion and societal discourse (Stieglitz and Dang-Xuan, 2013; Williams, et al., 2017). Ideas formed and spread in these settings can come to have impact also in other societal arenas. Consequently, user-generated content concerning IoT on social media can come to have impact on attitudes, understandings, and adoption of IoT technologies more broadly. Fundamentally, IoT might be particularly open to such discursive (re)constructions due to its vagueness as a concept.

Ustek-Spilda, et al. [4] note that "[t]he perils and promises of IoT do not exist in a vacuum". And thus, to gain insight into understandings of IoT on social media, it is not enough to merely explore what is being discussed but also take into account what is not, how understandings might have changed over time, and the impact of the social setting itself as well as broader societal factors. For these reasons, we approach the issue of IoT on Twitter form a discursive perspective.

Our inquiry departs from the premise that language use has the potential to affect our ideas, knowledge and values, and even influence societal structures (Wodak, 2015), while existing ideas, knowledge, values and societal structures concurrently constrain language use (Fairclough, 2010). This is not to say, however, that all language use is by default discourse, rather discourse is a repeated form of language use which has some level of commonality and prevalence in the social setting in which it is expressed. A discursive framework allows us to explore these patterns of language use.

Furthermore, it is important to acknowledge that user-generated content on social media tends to be highly shaped by a limited number of actors (Huffaker, 2010; see also Barabási and Albert, 1999). Therefore, considering that language use "gains power by the use powerful people make of it" [ㅁ] and that social media discussions are the product of user-generated content, it is imperative to pay specific attention to who is responsible for defining IoT on Twitter. To capture this complexity, we draw on sociotechnical perspectives (e.g., Bijker and Law, 1992) to identify and examine the most active human actors contributing to shaping the discourse, but also how the characteristics and limitations of non-human actors involved shaped the discourse (e.g., Hughes, 1994; Latour, 1996).

\section{Research design}


In this section, we outline our research design, including the paper's research context, and the process of data collection and analysis. Finally, we discuss the ethical considerations of the research.

\subsection{Research context}

The research context of this paper is the micro-blogging site Twitter. With its hundreds of millions of active users, Twitter is one of the world's largest social media platforms. Twitter's technological functions allow users to create personal accounts, "follow" and be "followed" by other users, send personal messages and post "tweets" - short public messages of up to 280 characters []]. The platform also allows users to react to other users' content. Users can comment on tweets through the reply function, retweet (repost) content and "like" other's tweets. Another key functionality of Twitter is the ability to label tweets with hashtags (\#) followed by text. Hashtags assign metadata to posts thus increasing searchability. They are used at different levels of abstraction, meaning and complexity (Zappavigna, 2015), and can be either spontaneous or part of planned strategies (Bruns and Burgess, 2015).

There is a relatively broad agreement in scholarly discourse that social media are important arenas in which to study emerging social processes and their implications. As noted, social media are important for the creation and spread of public opinion, and might even influence how societal issues are perceived globally (Balahur and Jacquet, 2015). Beyond this, exposure to content on these platforms can have impact also outside of the given social media setting. Previous research for instance shows how such exposure can concretely impact consumer attitudes (Duffett, 2017) and behaviors (Stephen, 2016). Correspondingly, using social media data, and Twitter specifically, to mine opinion about technology and specific organizations can be an effective strategy for corporations to better manage and develop sales strategies (Sharifi and Shokouhyar, 2021) and supply chains (Amirmokhtar Radi and Shokouhyar, 2021). Similarly, Twitter data can contribute to the understanding of IoT in ways which could be beneficial for academia as well as industry.

However, the very nature of social media constitutes methodological challenges for those conducting qualitative research. Social media platforms such as Twitter hold massive quantities of unstructured, short pieces of user-generated content and user data, created and stored independently of research efforts (Venturini and Latour, 2010). These conditions require new forms of adaptability in terms of research design in that methods need to be tailored to fit what information is accessible at any given time, and how it is composed (French and Shim, 2016). To address this challenge, we use Lindgren's (2016) connected concept analysis (CCA) - a method which draws on both quantitative and qualitative data analysis approaches to visualize discourse in large-scale datasets.

\subsection{Data collection}

The study draws on an initial dataset of 9,610,111 tweets along with related user information from 425,511 unique contributing Twitter users. The dataset, which was collected throughout the last week of March 2020, covers a sample period from 2008 []] through 2019 []]. Specifically, the dataset was sampled through the use of the hashtag \#IoT. As noted, hashtags are a way of labelling tweets for searchability and are important for organizing content on the platform. Sampling data via hashtags can thus be considered an efficient way of getting to the core of a topic on Twitter (Bruns and Burgess, 2015; Zappavigna, 2015).

To understand the emergence and evolution of IoT as a concept on Twitter, we temporally bracketed the dataset into two equally long periods (Langley, 1999). The first period spans from 2008 through 2013, and the later from 2014 through 2019. The sample period encompasses time in which interest in IoT steadily grew. However, while the annual number of academic publications on IoT started increasing in 2009, it did not exceed 100 until 2012 (Yan, et al., 2015), and it was not until 2014 that research efforts significantly intensified (Mishra, et al., 2016). Correspondingly, this increasing, yet for long limited interest in IoT, can also be identified in the sampled data as tweets posted between 2006 (2008) to 2013 make up just around 1.3 percent of the total body of tweets collected for this study. With this, the sample spanning these years constitute the burgeoning period in IoT discussions on Twitter, but the fact that the bulk of tweets collected were posted in the latter part of the sample period, nuances in earlier tweets would likely be overlooked if analyzed with a larger share of the dataset. Thus, to understand the emergence of IoT on Twitter, while still having some actual tweets to work with, an early time period for analysis was therefore limited the first half of the sample period, encompassing all tweets posted before 2014. In total, this meant 127,970 tweets. Throughout the analysis, we compared the discourse of IoT between these two periods, and the distribution of levels and types of activity within and between human and non-human actors (Latour, 1996).

\subsection{Data analysis}

To explore how IoT is understood over time on Twitter, we draw on connected concept analysis (CCA) approach as outlined by Lindgren (2016). The method provides an overview of datasets too big to analyze qualitatively, while at the same time enabling qualitative close readings oftentimes lacking in quantitative methods. The approach takes inspiration from several different qualitative and quantitative approaches - on 
constant comparative coding (Glaser, 1965) to form categories or themes, network analysis (Wasserman and Faust, 1994) to visualize them, and discourse theoretical terminology (Laclau and Mouffe, 2001) to understand them qualitatively. Specifically, the empirical analysis carried out in this paper, drawing inspiration from Lindgren (2016), was separated into three key steps: (1) tokenization and selection which included identifying the most commonly used words in the dataset's tweets after the removal of common stop words; (2) conceptualization which involved reading these most commonly occurring words in the context of the tweets in which they were used and thereafter coding them into discursive categories based on their subject and focus (see Table 1). Words which were coded into a category were re-labelled in the dataset as that discursive category. Hence, the categorizations took the place of those words in the analysis.; and finally (3) connection and visualization which involved creating a network to visualize the discourse identified through the coding in steps one and two. We conducted two separate CCA analyses following these three steps for the earlier (20082013), and latter (2014-2019) subsamples of the dataset.

\begin{tabular}{|c|c|c|}
\hline \multicolumn{3}{|c|}{ Table 1: Excerpts from CCA coding. } \\
\hline Word & $\begin{array}{l}\text { Excerpt from } \\
\text { tweets }\end{array}$ & $\begin{array}{l}\text { Defined discursive } \\
\text { categories }\end{array}$ \\
\hline $\begin{array}{l}\text { edge } \\
\text { edge } \\
\text { computing }\end{array}$ & $\begin{array}{l}\text { edge computing! } \\
\text { is it the next best } \\
\text { thing? is it just } \\
\text { buzzword? read } \\
\text { and learn! } \\
\text { \#edgecomputing } \\
\text { \#iot \#copperberg } \\
\text { [URL] }\end{array}$ & edge_computing \\
\hline apple & \begin{tabular}{|l} 
Apple dives \\
further into the \\
\#IoT with \\
\#iBeacons, \\
which launched \\
last week. Learn \\
more here. \\
[URL] \\
\end{tabular} & named_organisations \\
\hline miraiwatertemp & \begin{tabular}{|l} 
こんばんは \\
stopping update \\
because of dark. \\
see you. \\
\#goldfish \#金魚 \\
\#水温 \\
\#raspberrypi \\
\#miraiwatertemp \\
\#netthing \#iot \\
\#m2m 2015-09- \\
26 18:00:04
\end{tabular} & tweeting_bots \\
\hline $\begin{array}{l}\text { wsn; } \\
\text { rfid; } \\
\text { sensor/-s }\end{array}$ & $\begin{array}{l}\text { [Name]: true } \\
\text { potential of } \\
\text { sensor } \\
\text { technology is } \\
\text { massively under- } \\
\text { exploited \#IoT } \\
\text { \#wsn [URL]; } \\
\text { mit developing } \\
\text { solar powered } \\
\text { rfid sensors for } \\
\text { iot applications } \\
\text { read more: } \\
\text { [URL] @ [user } \\
\text { account] } \\
\text { \#research } \\
\text { \#rfidsensors } \\
\text { \#solarpowered }\end{array}$ & sensors \\
\hline
\end{tabular}




\begin{tabular}{|c|c|c|}
\hline & \begin{tabular}{|l} 
\#rfid \#sensors \\
\#photovoltaic \\
\#perovskitecells \\
\#rfidtags \#iot \\
\end{tabular} & \\
\hline green & $\begin{array}{l}\text { [Name]: Internet } \\
\text { of Things } 2010 \\
\text { - IOT for a } \\
\text { Green Planet }\end{array}$ & environment \\
\hline $\begin{array}{l}\text { cloud } \\
\text { cloud } \\
\text { computing }\end{array}$ & $\begin{array}{l}\text { cloud computing } \\
\text { service provider, } \\
\text { comport, shares } \\
\text { how iot in } \\
\text { healthcare helps } \\
\text { to improve the } \\
\text { patient } \\
\text { experience } \\
\text { [URL] via } \\
\text { @ [user account] } \\
\text { \#cloud } \\
\text { \#computing \#iot } \\
\text { \#healthcare } \\
\end{array}$ & cloud_computing \\
\hline $\begin{array}{l}\text { blockchain } \\
\text { bitcoin }\end{array}$ & \begin{tabular}{|l|} 
verizon sees \\
central role for \\
blockchain in iot \\
but not bitcoin \\
- \#iot - \\
{$[$ URL] } \\
mooncoin like \\
\#bitcoin \\
\#cryptoequity \\
\#millenials \#iot \\
\#money \#club \\
\#finance \#social \\
\#community \\
\#api \#market \\
\end{tabular} & cryptocurrency \\
\hline $\begin{array}{l}\text { wearable/-s } \\
\text { wearble tech }\end{array}$ & $\begin{array}{l}\text { mobile app } \\
\text { development } \\
\text { 2018: the year of } \\
\text { wearable devices } \\
\text { and iot [URL] } \\
\text { \#iot }\end{array}$ & wearables \\
\hline
\end{tabular}

While the cleaning, selection, and coding of the tweets relied on interpretation of their topics and focus, this process was carried out through close readings of thousands of tweets and is therefore considered to reflect the material in a plausible manner. The coding concluded, in accordance with the CCA method when saturation was reached - when new words no longer contributed to the construction of new categories but instead only increased the number of words belonging to each of the existing categories. At this point, as noted by Lindgren [9]: "new observations rarely add anything new to the conceptual structure that has been created, and at this point one must have the courage to stop".

The coded data was visualized using the Gephi software (Bastian, et al., 2009). The network generated through this process can be considered "a graphic visualization of a discourse" [10]. In network text analysis, the term "network" is understood as "a set of concepts and pairwise relations between them" where "different concepts play different roles depending on their position in the network" [11].

More concretely, each discursive category constitutes a "node" in the visualized network wherein the basis for determining whether a word or category was to be connected to another in the network was whether or not they co-occurred in the tweets. If they did, a so called "edge" or connection was created between them in the discursive visualization, and the more frequently categories co-occur the thicker the edge. 
In accordance with CCA we understand our visualizations through discourse theoretical terminology and accordingly, our epistemological and ontological assumptions in conducting the study are line with those of Laclau and Mouffe's discourse theory, which posits that rather than holding an inherent meaning, words are ascribed meaning through social interaction (see also Žižek, 1994), and that there is continuous struggle to fixate meaning, where some understandings become dominate.

Central to this is the idea of articulation. Laclau and Mouffe (2001) define this as "any practice establishing a relation among elements such that their identity is modified as a result of the articulatory practice" [12]. Correspondingly the discourse is then as a "system of differential positions" [13] or put in other words "the structured totality resulting from the articulatory practice" [14]. These positions in turn, are element of the discourse that have been articulated into moments [15], and especially "privileged" discursive positions [16] constituting the center of the discourse are conceptualized as nodal points. More concretely, a discourse then, is a temporarily fixed unified totality of language use made up of linguistic parts that become meaningful because of their interrelations. Through this fixed system, certain perspectives or ideas come to be legitimized, while others are peripheral or entirely excluded. Network analysis is used to visualize this fixation of meaning and the relations among different elements in the discourse. Following Lindgren (2016) we see moments as represented through the nodes in our visualized networks, and nodal points in particular, as the most central of these nodes in the networks. And the conceptual relations which tie these together are represented via the "edges" that connect nodes to create meaning.

Finally, to identify and generate an understanding for the role and prominence among the 425,511 unique actors in the dataset contributing to the construction of IoT on Twitter, and to capture change in their distribution over time, the 100 most active Twitter accounts in the earlier period (2008-2013), and in the later period (2014-2019) respectively, were categorized and analyzed. To do this, Twitter bios, profile photos and other content on user pages were analyzed based on Python operations in the dataset and manual searches through Twitter's API. By doing so, we could identify and distinguish human actors into principal categories and discover which type of non-human actors contributed under the \#IoT hashtag.

\subsection{Ethical considerations}

With the large volumes of user-generated data easily accessible through social media come a number of ethical considerations. Social media information is easy to trace both manually through API search functions and through various software. Hence, caution is warranted to protect the privacy of users. While social media data has sometimes been considered public data, it must be recognized that users might not be fully aware or comfortable with having this information used outside of the social setting for which it was intended (boyd and Crawford, 2012; Zimmer, 2018).

Ethical guidelines for internet research are increasingly available (franzke, et al., 2020), but official regulations in the area are lacking (Williams, et al., 2017). Instead, privacy concerns must be addressed and assessed individually, based on the research issue at hand. In line with the guidelines provided by Williams, et al. (2017), organizational and public figure accounts [17] were considered to be less sensitive, as they aim to reach vast audiences with their content. Similarly, bot accounts were also deemed less sensitive. Being automated, there is little reason to believe that they would face any negative repercussions by their content being published. Private user accounts were however treated with great concern for anonymity and privacy, and content which could be traced back to active accounts belonging to private individuals were omitted in the presentation of quotes in the paper.

\section{The evolution the IoT discourse on Twitter}

In what follows, we first discuss the changing IoT discourse on Twitter over the two time periods identified (4.1-4.2). To provide an overview of the central themes in the IoT discourse on Twitter over both periods we illustrate these using network visualizations [18]. Thereupon follows an analysis of the role and prominence of the actants (human and non-human actors) (see Latour, 1996) [19] involved in shaping the discourse during the two periods (4.3).

\subsection{Period 1 (2008-2013): IoT speculations of technological prospects}

Tweets posted during this first period contain an average of just two hashtags. The most popular among these hashtags (besides \#IoT) indicate an emphasis on technological objects. Specifically, the popularity of hashtags like \#nfc (near field communication), \#wsn (wireless sensor network), \#ipv6 (Internet protocol version 6), \#rfid (radio-frequency identification), \#arduino, \#sensors and \#technology illustrate a widespread hardware focus and concern for new versions of components such as sensors and new standardized protocols during the first period's discussions on IoT. 
There is a sparse number of reactions during this first period, which corresponds with the wider lack of interest in and knowledge of IoT both within academia and as seen in the limited number of tweets posted during this period. The tweets with the highest number of reactions throughout the entire first period generated only 99 retweets and 49 likes respectively. Beside general discussions about IoT technology, the most liked and retweeted content focused on speculations regarding the future impact of IoT, product promotion and new IoT tools. Among these most well-received tweets are for instance:

U drive a car? Own a fridge? Use iPad? Take medicine? Then the

"Internet of Things" affects yr life. Consultation: [URL] ... \#IoT

By 2020, Internet of Things cd connect 50 bn devices, from pallets to fridges. Video to \#IoTconf: [URL] \#IoT

Want to know what a tennis racquet circa 2050 might do? The Future of Social Objects [URL] \#IoT

\#IoT Toolkit and the Smart Object API for the Internet of Things [URL] \#opensource

Check out Adafruit's \#IoT Wi-Fi printer kit; includes @ [username] \& lets you print tweets: [URL] via @ [username]

The relative popularity of these tweets signals a curiosity among Twitter users regarding the potential future possibilities of IoT technology. More specifically, these well-received tweets focus on consumer benefits rather than large-scale organizational development and thus highlight a specific curiosity and interest in the prospects of individual and domestic use of IoT technology.

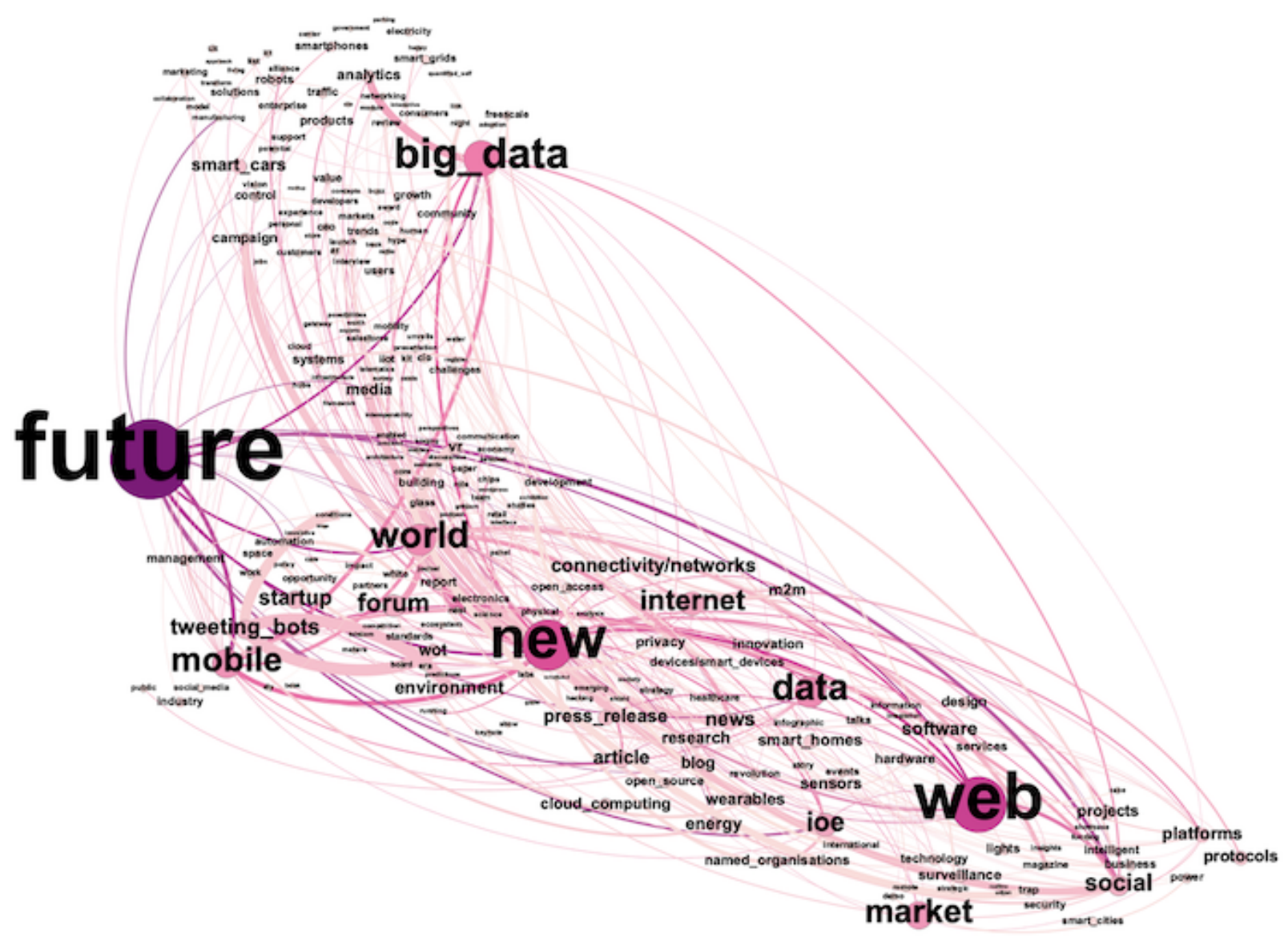

Figure 1: Overview of first sample period discursive network. 
Correspondingly, an examination of word co-occurrence in this first period reveals that the categories future, and new are among the nodes with highest prominence in the network along with the categories big data, Web. Thus, these discursive categories are the most highly connected, with greatest repetition, to other nodes in the network and therein constitute the discursive 'nodal points' of the first period (see Figure 1). This means, that during the first sample period, these are the categories around which much of the IoT discussion centers and comes to get its meaning.

Beyond the techno-enthusiasm illustrated in the most liked tweets of this period, the potentials of IoT as a highly impactful future technology is also seen through the visualization of the discursive network. Many tweets containing the primary nodal points future - which is the categorizations of the words and word pairs "future", "the future", "future of" and "future internet" - are unsurprisingly concerned with speculations about the future and novelty of IoT, with statements like "what does the future hold for the web?...", "joining sensors and big data to predict the future..." and "how will the future of big data impact the way we work and live?"

Being a nodal point, future is connected to most other categories in the discourse of IoT during the first period. The connections through edges between different categories are as mentioned based on whether categories occur together in the same tweets. The thicker the edge, the more frequent is the co-occurrence.

In Figure 1, the edges connecting future to the rest of the how it is frequently co-articulated with more specific thematic discursive 'moments' like mobile, data, and Web. These co-articulations are then often made in speculation of IoT's impact and future potentials for these areas:

The future of mobile is wherever, whenever [URL] \#IoT

Dreaming a future with more data available to us [URL] \#future \#technology \#displays \#IoT

What does the future hold for the web? http://bit.ly/1h8vh2d \#future \#IoT \#mobile [URL]

Extending the \#web. - a gaze into the \#future [URL] \#semanticweb \#IoT

With future predictions and prospective at the heart of the early period's discourse of IoT, it is perhaps not surprising that the idea of novelty is also central. This corresponds well to IoT's emergence and continuously increasing popularity and impact during this period in time. The interest in IoT as a technological novelty becomes especially evident through the prominence of the discursive nodal point new. The discursive category new - only incorporating the word "new" itself - is frequently co-articulated with the same discursive categories as future and is widely used to describe many IoT-related categories in the early period (see Figure 2). 


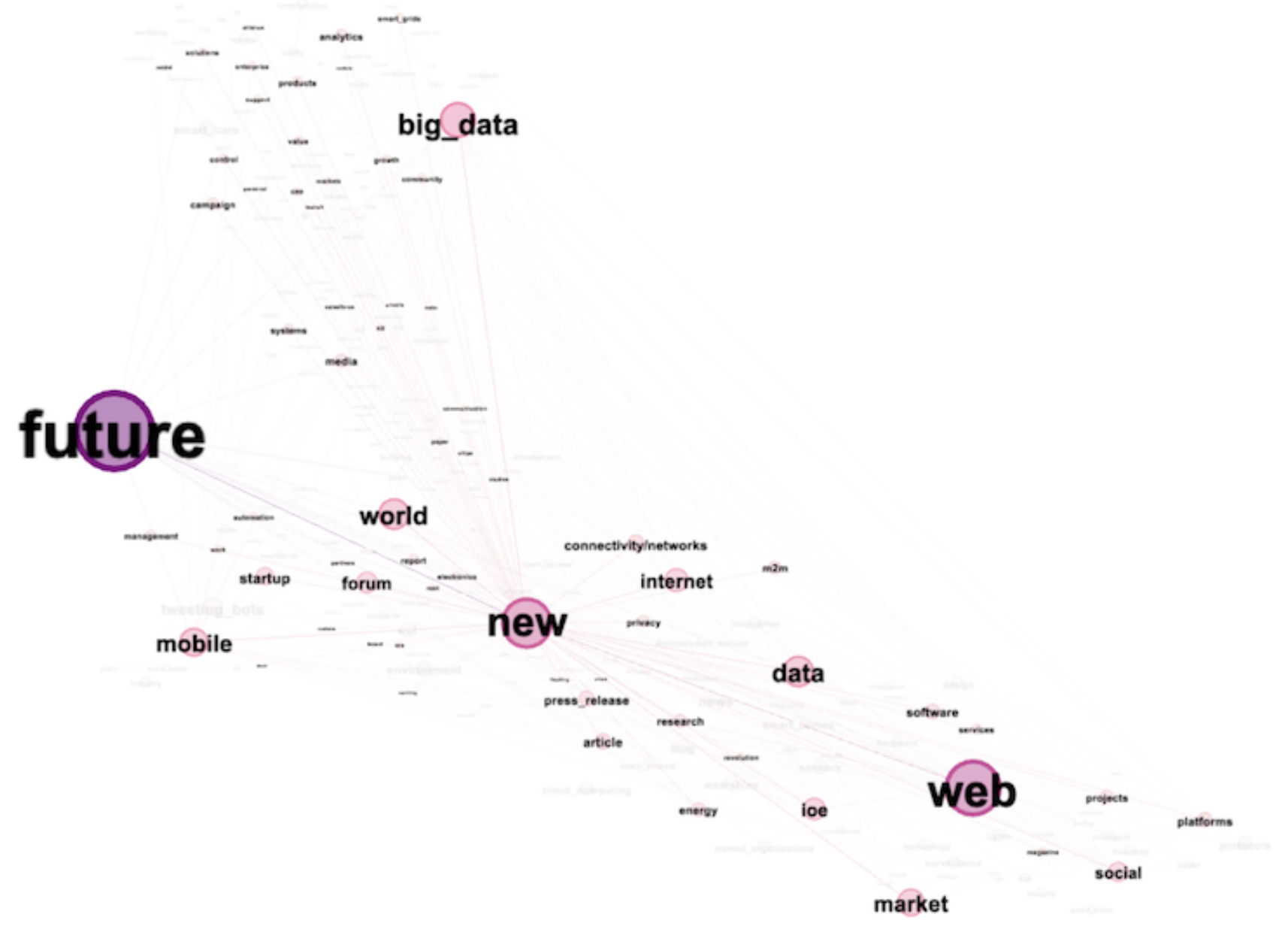

Figure 2: The "new" nodal point sub-discourse in the first sample period.

As the new nodal point becomes co-articulated with discursive categories that concern technical aspects of IoT implementation, their relational meaning emerging in Figure 2 signals that the novelty of IoT is often not related to IoT in a social or conceptual manner, but specifically in terms of technological innovation. As can be seen wherein the novelty category is coarticulated with such discursive moments as connectivity/networks, Internet, $m 2 m$ (machine to machine), software and platforms. For instance, this can be seen in tweets like:

Kick off the new year fully connected with these top \#IoT items:

[URL]

Things are the new apps for the internet [URL] \#IoT

ThingWorx version 4.0 is now available - makes building \#m2m and \#IoT apps even easier with new platform features - [URL]

NEC solution enables new machine to machine communication services \#IoT

why micro-location \#ibeacons may be Apple's biggest new feature for IOS 7 [URL] \#bigdata \#IoT

Intel chases internet of things with new chips, software [URL] \#IoT 
Finally, there is a dimension in some of this early period content, as for instance seen among the most liked and shared tweets during this period, that focus on technological aspects are also at times occurring at a grassroot level. Most notably, this spirit of technological enthusiasm can be noted in relation to DIY tips and hacks often connected to 3D printers and Arduino:

@ [username] offers new \#sensor development kit to apply \#mobile technology to the \#IoT: [URL]

Another cool hack from Arduino blog - flash / Arduino based speed detector [URL] \#IoT \#InternetofThings

reaDIYmate - DIY kits to build web-connected things [URL] \#IoT

Our 3D printer kit now available! everything you'd ever need to build a personal 3D printer \#IoT \#libelium \#diy [URL]

This signals that some of the content and ensuing discussions posted during this time can be characterized as micro-level technology tinkering by early adopters and those who are positive and enthusiastic of the personal value and benefits of IoT as an emerging technologic and hobby-type project.

In summary, the novelty of and enthusiasm towards IoT is evident in the early period. In line with previous research, a great deal of focus is with devices, standards, and technological solutions (Chae, 2019; Liu and Zhang, 2018; Zubiaga, et al., 2018). IoT is by and large treated as an engineering object in the sense that the discussions are typically focus on how, and with what tools, various components and modules can be combined into an IoT artifact. While large shares of the content concerns predictions and prospects of IoT technology, these are rooted in a technology centric engineering perspective rather than focusing on real world problems to be solved in order to create social or organizational values.

\subsection{Period 2 (2014-2019): IoT as a trigger for value creation}

Tweets posted during the second period received a considerably higher amount of attention. The most retweeted post was shared 6,162 times and the most liked post received 12,025 likes, likely due both to an increased use of Twitter and its functions overall but also specifically, this also showcase a greater interest in IoT. An increased use of hashtags could also be seen in excerpts of tweets throughout this section, which went from two on average in the first period to five in the latter.

During this later sample period, the most liked and shared content contain less speculation about the future. Promotion of specific products by organizations are highly liked and shared. Specifically, tweets concerning IoT product giveaways are among the most highly liked and retweeted, with calls like: "Want to WIN an Amazon Echo? Enter our giveaway", prompting users to "like and retweet" in order to participate in giveaways and competitions. This shift signals an increased interest during the second period, compared to the first, by large corporations to leverage IoT and bring attention to their own IoT endeavors and product developments through the use promotions and competitions. While such promotions could be seen during the first period too, they then mainly concerned with hardware. The most popular product promotions in this second period concern products which are bundles of software and hardware, ready to be used by mass market consumers (e.g., Amazon Echo). Clearly, commercial IoT-based products which are relatively affordable, easy to use, and satisfy latent customer needs are increasingly assimilated among non-specialist mass market consumers during this second period.

Beyond references to IoT products, the second period, unlike the first which saw lots of focus being placed on technological aspects of IoT, is dominated by content concerning contextual implementations of IoT, and the various consequences of these uses. This is notable in the use of hashtags during this period, with the most commonly occurring including for instance \#blockchain, \#cybersecurity, \#digitaltransformation and \#analytics. This shift in focus from IoT technology itself to discussions of how it can be leveraged for value creation is illustrated through the discursive network for this period (see Figure 3 ). 


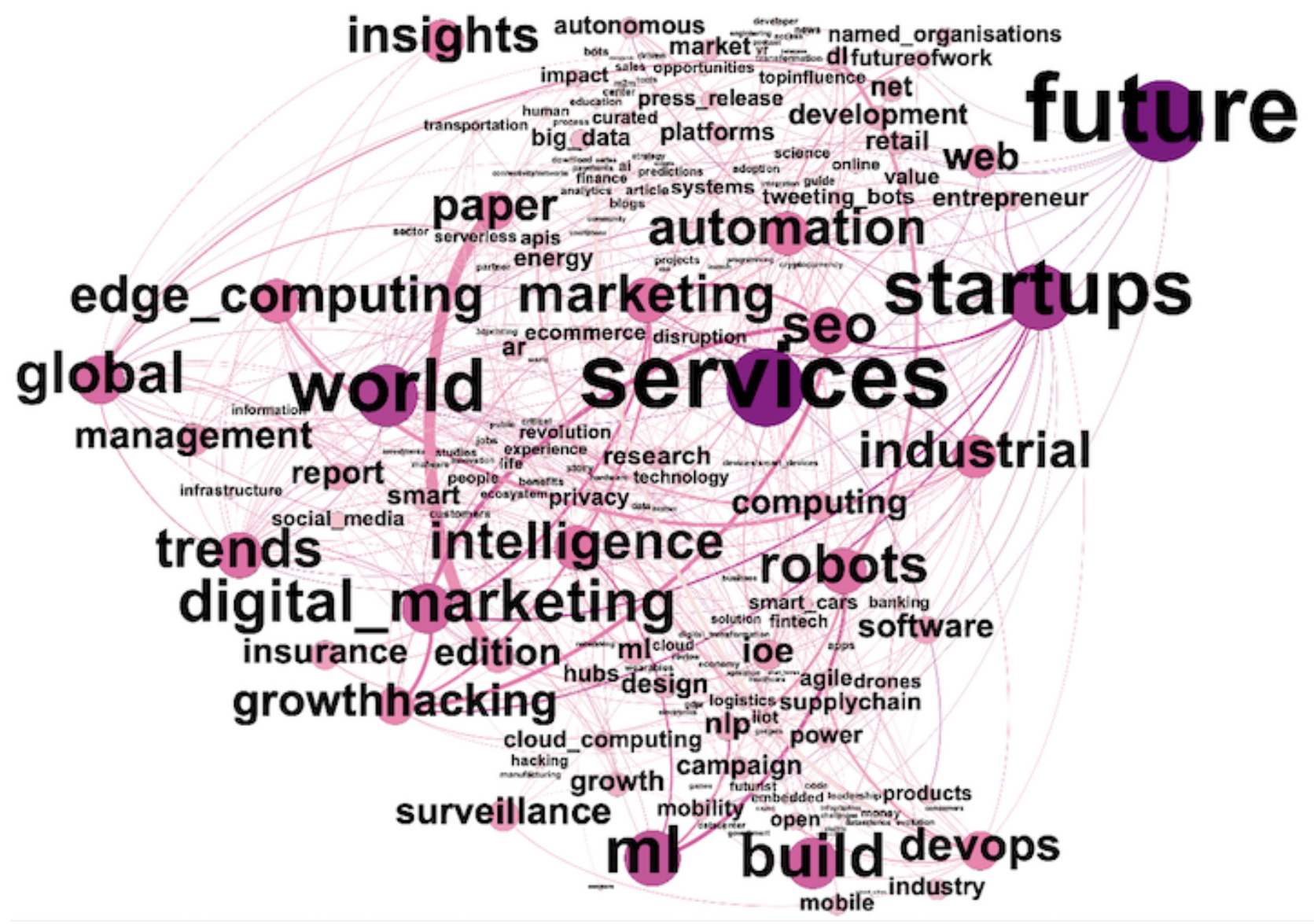

Figure 3: Overview of second sample period discursive network.

As illustrated by Figure 3, the IoT discourse not only appears much more expansive during this period compared to the first, but it also comprises numerous examples of applied IoT. This is for instance made clear by the contents of many tweets incorporating discursive moments such as automation, edge computing, and robots:

More \#automation, fewer \#jobs ahead [URL] \#cio \#IT \#tech \#InternetofThings \#IoT \# ITjobs

Main points: \#IOT is all about servicing the customer and automation. Thank you panelists! \#PygTech \#PygFest @ [username]

\#IoT value comes from the combination of edge computing and "the center." \#dataanalytics [URL]

HP Enterprise teams up with Intel for IoT edge computing [URL] \#IoT

After "taking" people's jobs, robots could soon replace guide dogs too [URL] \#IoT \#wearables

How tech leaders are looking to AI, IoT and robotics to fuel growth by 2021 [URL] \#AI \#IoT \#robotics \#tech \#growth

Besides this, in the second period, some of the most central discursive categories are startups and services. These constitute two of the prominent nodal points and indicate an importance in the entrepreneurial opportunities and current business trends in the context of IoT, respectively. Besides being the categories around which much of the discourse centers, they nevertheless form two separate yet related sub-discourses. 
First, the nodal point startups is closely connected to discursive moments such as marketing, growth hacking, and trends (see Figure 3 ). This chain of equivalence indicates a trend towards strategic marketing and business value of IoT in the period that indicate an importance in the current business trends in the context of IoT:

Do you have creative ideas and want to start your own company?

Well then follow us!!! We are a marketing agency for tech

startups. \#IoT

We've just had the pleasure of supporting \#IoT startup

@ [username] at @ [username] with marketing \& design

Marketing strategies for startups. We have series of marketing

plans for startup owners which can the take their business

online. \#microwidget \#digitalmarketing \#roi \#marketingstrategy

\#contentmarketing \#onlinepresence \#global \#branding \#IoT

free \#growthhacking tips for your \#startup [URL] \#tech \#saas

\#cloud \#devops \#IoT \#pr \#socialmedia \#entrepreneur \#startups

7 different areas of startup marketing where you can employ growth hacking tactics \#IoT

Venture Scanner's 15 Startup Market Reports and Databases with Trends and Insights: [URL] \#fintech \#ai \#IoT \#bitcoin

Are you paying attention to these

emerging \#manufacturing trends for 2016? [URL] \#startup \#IoT

What's hot in \#SiliconValley: \#IoT \#bigdata \#datasecurity

\#ehealth \#mobile \#startup \#entrepreneur \#trends

The context in which startups is most prominent, highlights an interest within the IoT industry to expand business opportunities, and a knowledge of the need to increase one's own exposure. More than this, there is a strand of tweets, especially those concerning marketing, where PR organizations and marketers have begun seeing the potentials of IoT ventures.

Second, the services category broadly focuses on business innovation and entrepreneurial opportunities within the field of IoT. It is frequently co-articulated with discursive moments like management and development:

A recent report by Transparency Market Research on the

global \#IoT \#fleet management market found

that \#smartphone integrated real-time data is driving demand for

fleet management services worldwide. \#telematics [URL]

The new intelligent systems service, an \#IoT offering built on

Microsoft \#Azure, offers secure management of \#bigdata [URL]

\#Technicolor launches \#VIRDATA for \#monitoring,

\#management and \#analytics of \#IoT \#m2m \#cloud service

[URL] \#IBM

How the rise of Digital Service Management is helping CIOs

handle technology chaos I information age [URL] \#IoT \#bigdata

assuring secure service management in the internet of

things \#IoT [URL] \# security \# servicemgmt

BMW signs on to develop in-car AI and IoT services with IBM's Watson [URL] \#IoT

here are seven tips from @ [username] for maximizing the probability of getting exactly what you want and expect from your \#IoT product development service provider. @ [username] [URL] 
The focus on services rather than hardware components, or even tangible commercial mass market products puts the issue of value creation at center stage as it is well established that customers' value creation processes are at the core of services due to their intangibility (see, for example, Vargo and Lusch, 2008).

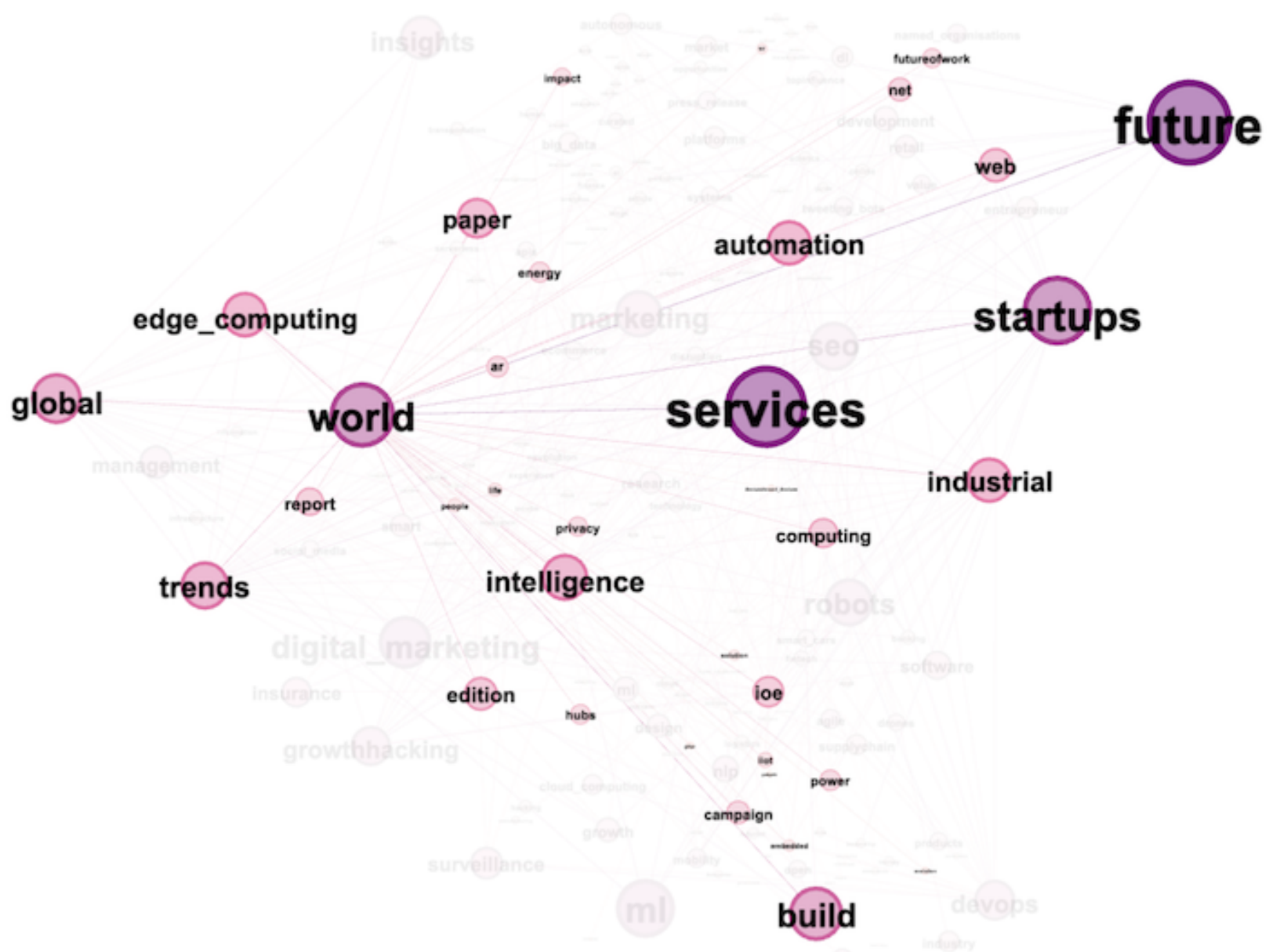

Figure 4: The "world" sub-discourse in the second sample period.

Beside these separate focuses, the two nodal points services and startup are also closely tied to an international perspective as illustrated by the extensive use of discursive moments like global and world. Beside the other nodal points, these categories are also co-articulated with a wide range of other discursive moments (see Figure 4). There was some focus in earlier tweets on the potential impact of IoT for "the world" through the discursive moment world during the first period (as illustrated in Figure 1 and Figure 2). However, in the second period, the discursive moments global and world. are frequently articulated with hashtags concerning readily available solutions enabling a more connected world:

The IoT revolution is changing the way companies around the world are doing business, helping them to work smarter and achieve better outcomes than ever before. here is how it is changing industries. [URL] \#industry4_0 \#technology \#AI \#IoT

Explore our internet of things. The IoT solutions world congress which brings together industry leaders to discuss how the industrial internet can be deployed, how it is already being used, and its many benefits. \#iot \#deloitte \#innovation [URL] 
\#industries worldwide gain even greater flexibility and choice to develop and implement tailored IoT solutions. [URL] \#iiot

Identiv releases connected IoT premises access control solution with its global partners: [URL] \#IoT

Explore China's internet of things market: In recent years, Global IoT markets have rapid development [URL] \#IoT

IDS's New Global \#IoT Decision Maker Survey Quantifies the IoT Opportunity [URL]

While the discourse appears considerably different in the latter period, some discursive categories, nevertheless remain nodal points in the IoT discourse throughout both sample periods. One example is future, which underlines the sustained importance of prospects and predictions concerning IoT throughout the entire 11-year sample period. And thus, signals that IoT has yet to reach the stage of being a mature technology and remains a project surface for various hopes and visions around a connected world. To summarize, the second period moves beyond the technological focus of the first period. Rather than an engineering object, IoT is seen as a trigger for value creation whereby the discourse centers around contextual implementations, strategic marketing, and business values associated with IoT. Throughout this second period there is a pervasive global focus, indicating the increased international importance of IoT.

\subsection{Underlying sociotechnical dynamics: The changing prominence of different actants}

It is well established that in online settings, few user accounts often contribute large shares of the content. In our dataset, 76 percent of user accounts posted five times or less, while the five most active user accounts posted 6,9 percent of all the content under the IoT hashtag. This is equivalent to a total of 667,631 tweets by these most prolific five users.

This section identifies and explores the role those who are most highly prominent in contributing to the discursive construction of IoT on Twitter, and analyses how these actants are distributed over the two periods in terms of levels of activity. In so doing, we focus specifically on the 100 most active user accounts during the first and second period, respectively.

Among the actants, we identify two distinct types of human actors and one type of non-human actor as contributing to constructing IoT as a concept on Twitter. The first type of human actor identified as individuals. This actor category contains both private individuals, who do not state any particular occupation within an IoT related field and professionals, who for instance tweet in their capacity as researchers, developers, or business leaders. Almost all those identified as individuals, both in earlier and later tweets, were classified as belonging to the professionals category. By their Twitter profiles it is evident that most of them work with IoT, as they frequently describe themselves by using words such as "keynote speaker" or "influencer" in their profile bios. Overall, as seen through observations of their Twitter feeds and profiles, IoT-related issues constitute the majority of their content also beyond the scope of the tweets sampled for this study.

The second type of human actor identified as organizations. Organizational accounts do not name any individuals in their bios, and typically refer to an official Web site with the same name as the Twitter account. These accounts include for instance news providers, companies, and non-profit organizations.

Finally, the non-human actor category identified is that of bots. Identifying and distinguishing Twitter bots from other types of accounts can be a daunting task. We drew upon the definition of bots as "accounts that can post content or interact with other user accounts in an automated way and without direct human input" [20]. Accordingly, we either identified bots based on their bios (e.g., containing the terms "fully-automated" or "robots") or through exceedingly repetitive, arranged, and active style of tweeting.

Throughout the two delineated sample periods, organizations often specifically focused on IoT products or services in their tweets. Their presence remained stable across the two periods, decreasing only by one percent from the first to the second period from 37 percent to 36 percent (see Table 2). While the prominence among organizations in defining IoT on Twitter remained consistent over time there are, however, considerably fewer individuals among the most active in the second sample period. In the first period, such accounts made up 60 percent of the 100 most active accounts. However, after 2014 they constitute only 35 percent of the most active accounts. The higher number of individual accounts during the first period can perhaps partially explain the technological enthusiasm of that period wherein there was an interest in IoT for personal use and the prominence of IoT micro-tinkering and DIY indicate that these early prominent users can be thought of as "early adopters" of IoT hardware. 


\begin{tabular}{|c|c|c|}
\hline & 2008-2013 & 2014-2019 \\
\hline & \multicolumn{2}{|c|}{ Top 100 most active accounts } \\
\hline bots & $3 \%$ & $29 \%$ \\
\hline individuals & $60 \%$ & $35 \%$ \\
\hline \multirow[t]{17}{*}{ organizations } & $37 \%$ & $36 \%$ \\
\hline & \multicolumn{2}{|c|}{ Most highly weighted categories } \\
\hline & category & category \\
\hline & future & future \\
\hline & web & services \\
\hline & new & startups \\
\hline & big data & world \\
\hline & world & $\mathrm{ml}$ \\
\hline & data & robots \\
\hline & mobile & build \\
\hline & market & $\begin{array}{l}\text { digital } \\
\text { marketing }\end{array}$ \\
\hline & internet & global \\
\hline & ioe & seo \\
\hline & tweeting bots & trends \\
\hline & forum & marketing \\
\hline & social & intelligence \\
\hline & connectivity/networks & industrial \\
\hline
\end{tabular}

While we found only three bots among the most active in the first period, they constitute almost a third, or 29 percent of the 100 most prolific accounts in the second sample period. Several bots were Brazilian traffic cameras, repeatedly tweeting images of their respective intersections. Others were for instance updating on time, news, weather, or fish tank temperatures.

In fact, a high number of hashtags among the most popular in the second period are used by IoT devices themselves. Brazilian traffic camera bots frequently used hashtags like \#ssp, \#communidade, \#florianopolis, \#sc405, \#riotavares, \#blumenau and \#itajai in 2016 and 2017. However, most likely due to their spam-like way of posting, many of these accounts received "unusual activity" warnings from Twitter. Many, if not all, of these accounts have since disappeared from the platform. There is no indication of their presence among the most common hashtags from 2018 and onward. Nevertheless, bots clearly replaced individuals in the second period. Undoubtedly, it is challenging for humans to compete with bots' relentless ability to tweet in great quantities: The most active bot tweeted 142,442 tweets, on average 266 tweets per day, the 535 days it was active. However, as seen in Figures $\underline{1}$ and $\underline{2}$, the content posted by bots seldomly co-occurs with other discursive categories. Thus, despite their high levels of activity, the content posted by bots did not result in centrality in the discursive network, and with this, it can be argued that it was not these tweets that had any impact in defining IoT during this period.

Relatedly, while we have distinguished and compared the key actants across the two periods, it is important to highlight that these actants' tweets were not necessarily the most liked and shared under the \#IoT hashtag. This becomes particularly clear in the second period. Closer scrutiny of the 100 most active actants in each period reveals that the number of reactions generated seems to be contingent on the type of actant. For instance, although bots dominate the second period in terms of number of tweets, many of their tweets do not generate any reactions or likes. Even the most active bots do, on average, not receive any likes or retweets. In contrast, among human actors the most active individuals generated on average between three and four likes and four retweets per tweet. 


\section{Concluding discussion}

Rapidly increasing speed, scale, and scope of the evolution of digital artifacts (e.g., Brynjolfsson and McAfee, 2014; Kurzweil, 2005) has expanded the arenas and variation of actants that contribute to the discourse around emerging technologies (Vaast, et al., 2013; Wang, 2010). By collecting and analyzing a large social media dataset drawing inspiration from CCA methodology (Lindgren, 2016), we sensitize a rich and structured empirical account of how the discourse of IoT was constructed on Twitter. This account contributes an understanding both of how IoT emerged and evolved as a discourse on Twitter over time, and the human and non-human actors that contributed to it doing so. To this end, our findings reveal a key significant change over time.

In the first period, IoT was discussed from an engineering perspective. For example, a significant number of tweets concerned new versions of components such as sensors and new standardized protocols. Among actants, individuals were the most active, and they broadly came across as "early adopters" of IoT hardware. Our findings illustrate how a large number of tweets (and ensuing discussions) in this period revolve around what can be characterized as micro-level technology tinkering. One example is discussions around how to build IoT solutions with Arduino (e.g., a speed detector) and various forms of DIY-kits related to IoT. It is therefore notable that tweets from the first period were very much aligned with early scholarly writings on IoT: The focus is on technological solutions, and IoT as a phenomenon is approached from an engineering perspective (Lee, et al., 2017; Olson, et al., 2015; Yan, et al., 2015).

Our network visualizations revealed how another set of categories were discursively co-articulated with IoT in the second period. Here, rather than new hardware and technological solutions, the focus shifted towards practical implementations in various forms of organizational contexts, and particularly ways of leveraging IoT solutions to cultivate service innovation and generate novel forms of value creation. Our categorization and analysis of the 100 most active actants revealed that organizations surpassed individuals during the second period. Yet, a majority of academic scholarship around IoT continues to apply an engineering perspective even in more recent years (Lee, et al., 2017; Olson, et al., 2015; Riggins and Wamba, 2015). Thus, we can speculate that going forward, it may rather be on social media that the critical, and cutting-edge ideas of IoT are cultivated, than in academic scholarship.

The study revealed a high presence of bots as non-human actors contributing to shaping the IoT discourse on Twitter, especially in recent years. This finding ties in with recent scholarly discussions around the accountability and agency of bots (de Lima Salge and Berente, 2017; Cresci, et al., 2021) which calls to revisit the nature and role of agency in the era of applied AI. To this end, the recent notion of algorithmic agency attempts to capture the novel dynamics occurring between human and technological agents in the enactment of AI in organizational contexts (e.g., Andersen, et al., 2016; Edwards, 2018). Algorithmic agency refers to the "capability of machines to act autonomously, but on behalf of humans, organizations and institutions" [21], through translating human inputs into binary code, interpreting data, and generating new data based on those very interpretations (Andersen, et al., 2016).

The presence of bots, and their algorithmic agency puts into new light the question of who has the power and resources to contribute to defining emerging technological concepts as algorithmic agency grants bots the capability of relentless tweeting. Still, in our dataset, while many of the bots effectively spammed Twitter with excessive content, we consider the overall absence of reactions as evidence of their relatively limited influence. However, looking forward at the future construction of emerging technological concepts, we echo the concerns raised by Wojcik, et al. (2018): the possibility to use bots for more insidious purposes than seen in this study, such as spreading misinformation, cannot be overstated as social media bots can also be used to purposefully alter public opinion (see also Varol, et al., 2017). Overall, an increase in the presence of bots tweeting about a technological concept can possibly mean an increase in the spread of certain information over others. By extension, and in our case, this also risks possibly clouding a human, interactive discourse of IoT on Twitter to the benefit of an exorbitant spread of repetitive content, possibly posted with political or organizations' strategic agendas in mind.

As IoT grows more pervasive, and its impact on individuals, organizations, and society increases (French and Shim, 2016; Newell and Marabelli, 2015), it is more critical than ever not only to comprehend which issues are incorporated into its discourse, but also which are not. While previous research exploring the issue of IoT on Twitter showcased the salience of security related issues (Bian, et al., 2016; Liu and Zhang, 2018; Zubiaga, et al., 2018), these remained somewhat absent in the visualizations of the IoT discourse in our dataset. The absence of such issues in our visualizations suggest that conversations about security, ethics, integrity, and privacy are not co-articulated with other topics, but instead appears as isolated discussions. Thus, while previous research has shown how these topics have garnered increased interest in social media discussions over 
time (Chae, 2019), the sampling made in this paper reveals that rather than being integrated parts of a wide range of conversations and IoT topics, issues of security, ethics, integrity, and privacy are treated by Twitter users as their own separate issues. While we can only speculate, it is reasonable to assume that security related issues will increasingly enter the discussion in a more integrated fashion as a more as the diffusion of IoT increases, and thus the commercial viability of security offerings. Similarly, discussions around ethics, integrity, and privacy may increase once a certain level of IoT integration has occurred in our daily lives.

To conclude, our use of CCA (Lindgren, 2016) provided an overview of the comprehensive IoT dataset incorporating more than nine million tweets and sample period spanning over more than a decade, while at the same time allowing us to do the qualitative close readings that are oftentimes lacking in quantitative methods. With a discursive perspective on IoT we have argued that social media discussions about an ambiguous and "fuzzy" concept like "the Internet of Things" have the potential to challenge hegemonic understandings of the concept also in other parts of society. The focus on discourse as well as its underlying sociotechnical dynamics provided a unique insight, beyond that of previous research, not only into how the IoT discourse was shaped over time, but by whom.

\section{Limitations and future research}

Seeking to provide a large-scale overview, it was not within the scope of this study to analyze the content of shared links or explore in depth the use of Twitter's functionalities. Future studies would therefore do well in providing insight into such aspects. Indeed, mapping the development and change of hashtag use would also be valuable for both research and industry. With regards to the role of non-human actors, such as bots, in contributing the construction of emerging technological concepts on social media, we encourage scholars to conduct more detailed and deepened inquiries into how this development can be understood by further theorizing the notion of algorithmic agency. Since the majority of current writings on this construct remain conceptual, it opens up substantial opportunities for theory development on the individual, organizational, and societal implications of bots as a type of AI. It would be particularly interesting to generate further empirically anchored understandings of how algorithmic and human agency intermingle in such contexts. Em

\section{About the authors}

Mathilda Åkerlund is a Ph.D. candidate in sociology at Umeå University. Her research interests concern digital culture and research methods.

E-mail: mathilda [dot] akerlund [at] umu [dot] se

Daniel Nylén is Associate Professor at Swedish Center for Digital Innovation, Department of Informatics, Umeå University.

ORCID: https://orcid.org/0000-0002-4895-5493

E-mail: daniel [dot] nylen [at] umu [dot] se

Notes

1. Atzori, et al., 2010, p. 2,788.

2. Singh, et al., 2014, p. 287.

3. Lee, et al., 2017, p. 1,057.

4. Ustek-Spilda, et al., 2021, p. 137.

5. Wodak, 2009, p. 35.

6. The 140-character limit was removed in 2017 for tweets not in Korean, Chinese or Japanese (see https://blog.twitter.com/official/en us/topics/product/2017/tweetingmadeeasier.html).

7. Data was collected from 2006 but there was no activity to be collected before 2008 . This lack of tweets before 2008 was confirmed by a manual search on Twitter.

8. Since data was collected after the actual time period studied, it should be acknowledged that tweets might have been deleted before data collection began.

9. Lindgren, 2016, p. 348. 
10. Lindgren, 2016, p. 358.

11. Carley, 1997, pp. 79, 81 .

12. Laclau and Mouffe, 2001, p. 105.

13. Laclau and Mouffe, 2001, p. 102.

14. Laclau and Mouffe, 2001, p. 105.

15. Ibid.

16. Laclau and Mouffe, 2001, p. 112.

17. Organisations and public figures were recognised as those accounts having Twitter's "blue verified badge" in their profile, as this is an official verification of their authenticity and publicness

(see https://help.twitter.com/en/managing-your-account/about-twitter-verified-accounts).

18. The network visualizations presented are undirected. Node colors and sizes are based on weighted degrees, where higher degree means darker color, and large nodes. This means that those discursive categories that cooccur often with a large number of other categories in tweets, are a darker shade. The re-occurrences of these connections are visualized through edge weights, which represents weight of each undirected edge. Edge weights in terms of thickness are based on how often words and concepts co-occur within the same tweets. IoT as a node has been excluded from the visualizations for clarity and the edge weight limit is set to show the two percent most central categories, Layout algorithm is Yifan Hu.

19. Following Latour (1996) we will hereafter use the term "actants" when referring to human and non-human actors simultaneously while "actor(s)" is used when referring only to either human or non-human actors.

20. Wojcik, et al., 2018, p. 4.

21. Ågerfalk, 2020, p. 5 .

\section{References}

V. Adat and B.B. Gupta, 2018. "Security in Internet of Things: Issues, challenges, taxonomy, and architecture," Telecommunication Systems, volume 67, number 3, pp. 423-441.

doi: https://doi.org/10.1007/s11235-017-0345-9, accessed 2 December 2021.

P.J. Ågerfalk, 2020. “Artificial intelligence as digital agency,” European Journal of Information Systems, volume 29 , number 1 , pp. $1-8$. doi: https://doi.org/10.1080/0960085X.2020.1721947, accessed 2 December 2021.

S. Amirmokhtar Radi and S. Shokouhyar, 2021. "Toward consumer perception of cellphones sustainability: A social media analytics," Sustainable Production and Consumption, volume 25, pp. 217-233.

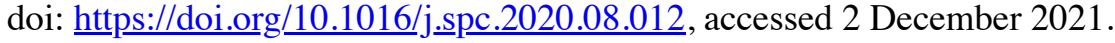

J.V. Andersen, A. Lindberg, R. Lindgren, and L. Selander, 2016. "Algorithmic agency in information systems: Research opportunities for data analytics of digital traces," 2016 49th Hawaii International Conference on System Sciences (HICSS).

doi: https://doi.org/10.1109/HICSS.2016.571, accessed 2 December 2021.

K. Ashton, 2009. "That 'Internet of Things' thing," RFID Journal, at https://www.rfidjournal.com, accessed 2 December 2021.

L. Atzori, A. Iera, and G. Morabito, 2010. "The Internet of Things: A survey," Computer Networks, volume 54, number 15 , pp. 2,787-2,805.

doi: https://doi.org/10.1016/j.comnet.2010.05.010, accessed 2 December 2021.

A. Balahur and G. Jacquet, 2015. "Sentiment analysis meets social media - Challenges and solutions of the field in view of the current information sharing context," Information Processing \& Management, volume 51, number 4, pp. 428-432.

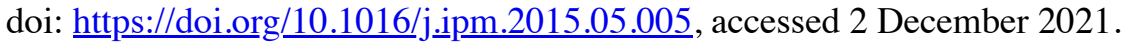


A.-L. Barabási and R. Albert, 1999. "Emergence of scaling in random networks," Science, volume 286, number 5439 (15 October), pp. 509-512.

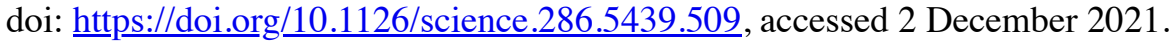

M. Bastian, S. Heymann, and M. Jacomy, 2009. "Gephi: An open source software for exploring and manipulating networks," at https://gephi.org/publications/gephi-bastian-feb09.pdf, accessed 2 December 2021.

J. Bian, K. Yoshigoe, A. Hicks, J. Yuan, Z. He, M. Xie, Y. Guo, M Prosperi, R. Salloum, and F. Modave, 2016. "Mining Twitter to assess the public perception of the 'Internet of Things', 'PLOS ONE, volume 11, number 7 (8 July), e158450.

doi: https://doi.org/10.1371/journal.pone.0158450, accessed 2 December 2021.

W.E. Bijker and J. Law (editors), 1992. Shaping technology/building society: Studies in sociotechnical change. Cambridge, Mass.: MIT Press.

d. boyd and K. Crawford, 2012. "Critical questions for big data: Provocations for a cultural, technological, and scholarly phenomenon," Information, Communication \& Society, volume 15, number 5, pp. 662-679. doi: https://doi.org/10.1080/1369118X.2012.678878, accessed 2 December 2021.

C. Brewster, I. Roussaki, N. Kalatzis, K. Doolin, and K. Ellis, 2017. "IoT in agriculture: Designing a Europewide large-scale pilot," IEEE Communications, volume 55, number 9, pp. 26-33.

doi: https://doi.org/10.1109/MCOM.2017.1600528, accessed 2 December 2021.

A. Bruns and J. Burgess, 2015. "Twitter hashtags from ad hoc to calculated publics," In: N. Rambukkana (editor). Hashtag publics: The power and politics of discursive networks. Bern: Peter Lang, pp. 13-28.

E. Brynjolfsson and A. McAfee, 2014. The second machine age: Work, progress, and prosperity in a time of brilliant technologies. New York: Norton.

K.M. Carley, 1997. "Network text analysis: The network position of concepts," In: C.W. Roberts (editor). Text analysis for the social sciences: Methods for drawing statistical inferences from texts and transcripts.

Mahwah, N.J.: Erlbaum, pp. 79-100.

doi: https://doi.org/10.4324/9781003064060, accessed 2 December 2021.

B. Chae, 2019. "The evolution of the Internet of Things (IoT): A computational text analysis," Telecommunications Policy, volume 43, number 10, 101848. doi: https://doi.org/10.1016/j.telpol.2019.101848, accessed 2 December 2021.

K. Chen and D. Tomblin, 2021. "Using data from Reddit, public deliberation, and surveys to measure public opinion about autonomous vehicles," Public Opinion Quarterly, volume 85, number S1, pp. 289-322. doi: https://doi.org/10.1093/poq/nfab021, accessed 2 December 2021.

S. Cresci, M. Petrocchi, A. Spognardi, and S. Tognazzi, 2021. "The coming age of adversarial social bot detection," First Monday, volume 26, number 7, at https://firstmonday.org/article/view/11474/10139, accessed 2 December 2021.

doi: https://doi.org/10.5210/fm.v26i7.11474, accessed 2 December 2021.

C.A. de Lima Salge and N. Berente, 2017. "Is that social bot behaving unethically?" Communications of the $A C M$ volume 60 , number 9 , pp. 29-31.

doi: https://doi.org/10.1145/3126492, accessed 2 December 2021.

X. Dong and Y. Lian, 2021. "A review of social media-based public opinion analyses: Challenges and recommendations," Technology in Society, volume 67, 101724.

doi: https://doi.org/10.1016/j.techsoc.2021.101724, accessed 2 December 2021.

X. Dong, Y. Chang, Y. Wang, and J. Yan, 2017. "Understanding usage of Internet of Things (IOT) systems in China: Cognitive experience and affect experience as moderator," Information Technology \& People, volume 30 , number 1 , pp. $117-138$.

doi: https://doi.org/10.1108/ITP-11-2015-0272, accessed 2 December 2021.

R.G. Duffett, 2017. "Influence of social media marketing communications on young consumers'

attitudes," Young Consumers, volume 18, number 1, pp. 19-39.

doi: https://doi.org/10.1108/YC-07-2016-00622, accessed 2 December 2021.

P.N. Edwards, 2018. "We have been assimilated: Some principles for thinking about algorithmic systems," In: U. Schultze, M. Aanestad, M. Mähring, C. Østerlund, and K. Riemer (editors). Living with monsters? Social implications of algorithmic phenomena, hybrid agency, and the performativity of technology. Cham, 
Switzerland: Springer International. pp. 19-27.

doi: https://doi.org/10.1007/978-3-030-04091-8 3, accessed 2 December 2021.

N. Fairclough, 2010. Critical discourse analysis: The critical study of language. Second edition. London: Routledge. doi: https://doi.org/10.4324/9781315834368, accessed 2 December 2021.

B. Farahani, F. Firouzi, V. Chang, M. Badaroglu, N. Constant, and K. Mankodiya, 2018. "Towards fog-driven IoT eHealth: Promises and challenges of IoT in medicine and healthcare," Future Generation Computer Systems, volume 78, part 2, pp. 659-676. doi: https://doi.org/10.1016/j.future.2017.04.036, accessed 2 December 2021.

P. Fraga-Lamas, T. Fernndez-Caramés, M. Suárez-Albela, L. Castedo, and M. González-López, 2016. “A review on Internet of Things for defense and public safety," Sensors, volume 16, number 10, 1644. doi: https://doi.org/10.3390/s16101644, accessed 2 December 2021.

a.s. franzke, A. Bechmann, M. Zimmer, C. Ess, and the Association of Internet Researchers, 2020. "Internet research: Ethical guidelines 3.0," at https://aoir.org/reports/ethics3.pdf, accessed 2 December 2021.

A.M. French and J.P. Shim, 2016. "The digital revolution: Internet of Things, 5G and beyond," Communications of the Association for Information Systems, volume 38, pp. 840-850. doi: https://doi.org/10.17705/1CAIS.03840, accessed 2 December 2021.

B.G. Glaser, 1965. "The constant comparative method of qualitative analysis," Social Problems, volume 12, number 4, pp. 436-445.

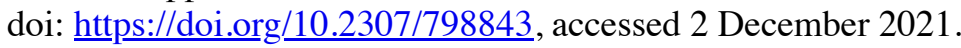

N. Goumagias, J. Whalley, O. Dilaver, and J. Cunningham, 2021. "Making sense of the internet of things: A critical review of internet of things definitions between 2005 and 2019," Internet Research, volume 31, number 5, pp. 1,583-1,610.

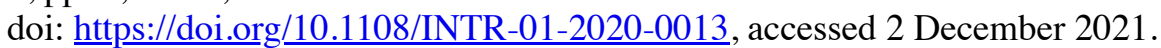

J. Gubbi, R. Buyya, S. Marusic, and M. Palaniswami, 2013. "Internet of Things (IoT): A vision, architectural elements, and future directions," Future Generation Computer Systems, volume 29, number 7, pp. 1,6451,660 .

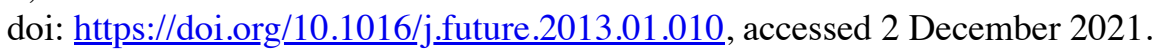

D. Huffaker, 2010. "Dimensions of leadership and social influence in online communities," Human Communication Research, volume 36, number 4, pp. 593-617.

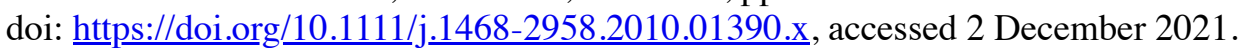

T.P. Hughes, 1994. “Technological momentum,” In: M.R. Smith and L. Marx (editors). Does technology drive history? The dilemma of technological determinism. Cambridge, Mass.: MIT Press, pp. 101-113.

T. Kadylak and S.R. Cotten, 2020. “United States older adults' willingness to use emerging technologies," Information, Communication \& Society, volume 23, number 5, pp. 736-750. doi: https://doi.org/10.1080/1369118X.2020.1713848, accessed 2 December 2021.

G.C. Kane, M. Alavi, G. Labianca, and S.P. Borgatti, 2014. "What's different about social media networks? A framework and research agenda," MIS Quarterly, volume 38, number 1, pp. 274-304. doi: https://doi.org/10.25300/MISQ/2014/38.1.13, accessed 2 December 2021.

R. Kumar, A. Anand, P. Kumar, and R.K. Kumar, 2020. "Internet of Things and social media: A review of literature and validation from Twitter Analytics," 2020 International Conference on Emerging Smart Computing and Informatics (ESCI), pp. 158-163.

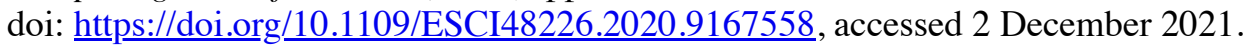

R. Kurzweil, 2005. The singularity is near: When humans transcend biology. New York: Viking.

E. Laclau and C. Mouffe, 2001. Hegemony and socialist strategy: Towards a radical democratic politics. Second edition. London: Verso.

A. Langley, 1999. "Strategies for theorizing from process data," Academy of Management Review, volume 24, number 4, pp. 691-710.

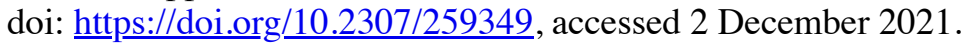


B. Latour, 1996. "On actor-network theory: a few clarifications," Soziale Welt, volume 47, number 4, pp. 369381.

S.-E. Lee, M. Choi, and S. Kim, 2017. "How and what to study about IoT: Research trends and future directions from the perspective of social science," Telecommunications Policy, volume 41, number 10, pp. $1,056-1,067$. doi: https://doi.org/10.1016/j.telpol.2017.09.007, accessed 2 December 2021.

S. Lindgren, 2016. "Introducing connected concept analysis: A network approach to big text datasets," Text \& Talk, volume 36, number 3 (30 April). doi: https://doi.org/10.1515/text-2016-0016, accessed 2 December 2021.

Z. Liu and M. Zhang, 2018. "Analysing online platform users' attitudes toward Internet of Things," Proceedings of the 22nd Pacific Asia Conference on Information Systems (PACIS 2018), at https://aisel.aisnet.org/pacis2018/192/, accessed 2 December 2021.

M.-H. Maras, 2015. "Internet of Things: Security and privacy implications," International Data Privacy Law, volume 5, number 2, pp. 99-104.

doi: https://doi.org/10.1093/idpl/ipv004, accessed 2 December 2021.

D. Mishra, A. Gunasekaran, S.J. Childe, T. Papadopoulos, R. Dubey, and S. Wamba, 2016. "Vision, applications and future challenges of Internet of Things: A bibliometric study of the recent literature," Industrial Management \& Data Systems, volume 116, number 7, pp. 1,331-1,355. doi: https://doi.org/10.1108/IMDS-11-2015-0478, accessed 2 December 2021.

I. Mohanraj, K. Ashokumar, and J. Naren, 2016. "Field monitoring and automation using IOT in agriculture domain," Procedia Computer Science, volume 93, pp. 931-939. doi: https://doi.org/10.1016/j.procs.2016.07.275, accessed 2 December 2021.

S. Newell and M. Marabelli, 2015. "Strategic opportunities (and challenges) of algorithmic decision-making: A call for action on the long-term societal effects of 'datification'," Journal of Strategic Information Systems, volume 24 , number 1 , pp. 3-14.

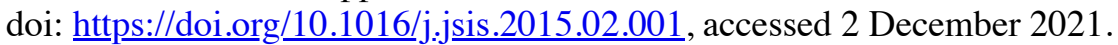

R. Nicolescu, M. Huth, P. Radanliev, and D.D. Roure, 2018. "Mapping the values of IoT," Journal of Information Technology?, volume 33, number 4, pp. 345-360. doi: https://doi.org/10.1057/s41265-018-0054-1, accessed 2 December 2021.

N. Olson, J.M. Nolin, and G. Nelhans, 2015. "Semantic Web, ubiquitous computing, or Internet of things? A macro-analysis of scholarly publications," Journal of Documentation, volume 71, number 5, pp. 884-916. doi: https://doi.org/10.1108/JD-03-2013-0033, accessed 2 December 2021.

M. Payal, P. Dixit, T.V.M. Sairam, and N. Goyal, 2021. "Robotics, AI, and the IoT in defense systems," In: A.K. Dubey, A. Kumar, S.R. Kumar, N. Gayathri, P. Das (editors). AI and IoT-based intelligent automation in robotics. Boston, Mass.: Scrivener Publishing, pp. 109-128.

doi: https://doi.org/10.1002/9781119711230.ch7, accessed 2 December 2021.

F.J. Riggins and S.F. Wamba, 2015. "Research directions on the adoption, usage, and impact of the Internet of Things through the Uue of big data analytics," 2015 48th Hawaii International Conference on System Sciences, pp. 1,531-1,540.

doi: https://doi.org/10.1109/HICSS.2015.186, accessed 2 December 2021.

A.M. Said, A. Yahyaoui, and T. Abdellatif, 2021. "Efficient anomaly detection for smart hospital IoT systems," Sensors, volume 21, number 4, 1026.

doi: https://doi.org/10.3390/s21041026, accessed 2 December 2021.

Z. Sharifi and S. Shokouhyar, 2021. "Promoting consumer's attitude toward refurbished mobile phones: A social media analytics approach," Resources, Conservation and Recycling, volume 167, 105398. doi: https://doi.org/10.1016/j.resconrec.2021.105398, accessed 2 December 2021.

D. Singh, G. Tripathi, and A.J. Jara, 2014. "A survey of Internet-of-Things: Future vision, architecture, challenges and services," 2014 IEEE World Forum on Internet of Things (WF-IoT), pp. 287-292. doi: https://doi.org/10.1109/WF-IoT.2014.6803174, accessed 2 December 2021.

A.T. Stephen, 2016. "The role of digital and social media marketing in consumer behavior," Current Opinion in Psychology, volume 10, pp. 17-21.

doi: https://doi.org/10.1016/j.copsyc.2015.10.016, accessed 2 December 2021. 
S. Stieglitz and L. Dang-Xuan, 2013. "Emotions and information diffusion in social media - Sentiment of microblogs and sharing behavior," Journal of Management Information Systems, volume 29, number 4, pp. 217-248.

doi: https://doi.org/10.2753/MIS0742-1222290408, accessed 2 December 2021.

F. Ustek-Spilda, D. Vega, M. Magnani, L. Rossi, I. Shklovski, S. Lehuede, and A. Powell, 2021. "A Twitterbased study of the European Internet of Things," Information Systems Frontiers, volume 23, number 1, pp. $135-149$.

doi: https://doi.org/10.1007/s10796-020-10008-5, accessed 2 December 2021.

E. Vaast, E.J. Davidson, and T. Mattson, 2013. "Talking about technology: The emergence of a new actor category through new media," MIS Quarterly, volume 37, number 4, pp. 1,069-1,092, and at https://misq.org/talking-about-technology-the-emergence-of-a-new-actor-category-through-new-media.html, accessed 2 December 2021.

A.J.A.M. van Deursen, A. van der Zeeuw, P. de Boer, G. Jansen, and T. van Rompay, 2021. "Digital inequalities in the Internet of Things: Differences in attitudes, material access, skills, and usage," Information, Communication \& Society, volume 24, number 2, pp. 258-276.

doi: https://doi.org/10.1080/1369118X.2019.1646777, accessed 2 December 2021.

S.L. Vargo and R.F. Lusch, 2008. "Service-dominant logic: Continuing the evolution," Journal of the Academy of Marketing Science, volume 36, pp. 1-10.

doi: https://doi.org/10.1007/s11747-007-0069-6, accessed 2 December 2021.

O. Varol, E. Ferrara, C.A. Davis, F. Menczer, and A. Flammini, 2017. "Online human-bot interactions: Detection, estimation, and characterization," Proceedings of the Eleventh International AAAI Conference on Web and Social Media (ICWSM 2017), pp. 280-289, and at https://aaai.org/ocs/index.php/ICWSM/ICWSM17/paper/view/15587/14817, accessed 2 December 2021.

O. Velsberg, U.H. Westergren, and K. Jonsson, 2020. "Exploring smartness in public sector innovation Creating smart public services with the Internet of Things," European Journal of Information Systems, volume 20 , number 4, pp. 350-368.

doi: https://doi.org/10.1080/0960085X.2020.1761272, accessed 2 December 2021.

T. Venturini and B. Latour, 2010. "The social fabric: Digital traces and quali-quantitative methods," Proceedings of Future En Seine: The Digital Future of the City, pp. 15-30, and at https://medialab.sciencespo.fr/publications/the-social-fabric-digital-traces-and-quali-quantitative-methods/, accessed 2 December 2021.

P. Wang, 2010. Chasing the hottest IT: Effects of information technology fashion on organizations, MIS Quarterly, volume 34, number 1, pp. 63-85.

doi: https://doi.org/10.2307/20721415, accessed 2 December 2021.

S. Wasserman and K. Faust, 1994. Social network analysis: Methods and applications. Cambridge: Cambridge University Press.

doi: https://doi.org/10.1017/CBO9780511815478, accessed 2 December 2021.

M.L. Williams, P. Burnap, and L. Sloan, 2017. "Towards an ethical framework for publishing Twitter data in social research: Taking into account users' views, online context and algorithmic estimation," Sociology, volume 51, number 6, pp. 1,149-1,168.

doi: https://doi.org/10.1177/0038038517708140, accessed 2 December 2021.

R. Wodak, 2015. The politics of fear: What right-wing populist discourses mean. London: Sage.

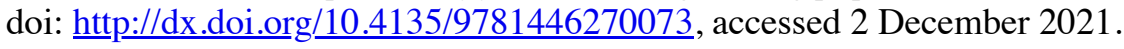

R. Wodak, 2009. The discourse of politics in action: Politics as usual. Basingstoke: Palgrave Macmillan.

S. Wojcik, S. Messing, A. Smith, L. Rainie, and P. Hitlin, 2018. "Bots in the Twittersphere," Pew Research Center (9 April), at https://www.pewresearch.org/internet/2018/04/09/bots-in-the-twittersphere/, accessed 2 December 2021.

F. Wortmann and K. Flüchter, 2015. "Internet of Things: Technology and value added," Business \& Information Systems Engineering, volume 57, number 3, pp. 221-224. doi: https://doi.org/10.1007/s12599-015-0383-3, accessed 2 December 2021.

B.-N. Yan, T.-S. Lee, and T.-P. Lee, 2015. "Mapping the intellectual structure of the Internet of Things (IoT) field (2000-2014): A co-word analysis," Scientometrics, volume 105, number 2, pp. 1,285-1,300. 
doi: https://doi.org/10.1007/s11192-015-1740-1, accessed 2 December 2021.

K.H. Yeh, 2016. "A secure IoT-based healthcare system with body sensor networks," IEEE Access, volume 4, pp. 10,288-10,299.

doi: https://doi.org/10.1109/ACCESS.2016.2638038, accessed 2 December 2021.

M. Zappavigna, 2015. "Searchable talk: The linguistic functions of hashtags," Social Semiotics, volume 25, number 3, pp. 274-291.

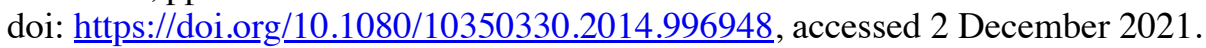

M. Zimmer, 2018. "Addressing conceptual gaps in big data research ethics: An application of contextual integrity," Social Media + Society (2 May).

doi: https://doi.org/10.1177/2056305118768300, accessed 2 December 2021.

S. Žižek, 1994. Mapping ideology. London: Verso.

A. Zubiaga, R. Procter, and C. Maple, 2018. "A longitudinal analysis of the public perception of the opportunities and challenges of the Internet of Things," PLOS ONE, volume 13, number 12 (20 December), e0209472.

doi: https://doi.org/10.1371/journal.pone.0209472, accessed 2 December 2021.

\section{Editorial history}

Received 1 December 2020; revised 14 October 2021; accepted 30 November 2021.

Copyright (C) 2021, Mathilda Åkerlund and Daniel Nylén. All Rights Reserved.

From technology speculation to value creation: The changing discourse and actants in the construction of IoT on Twitter

by Mathilda Åkerlund and Daniel Nylén.

First Monday, Volume 26, Number 12 - 6 December 2021

https://firstmonday.org/ojs/index.php/fm/article/download/11485/10543

doi: https://dx.doi.org/10.5210/fm.v26i12.11485 